\title{
Editorial
}

\section{Saúde mental dos estudantes de medicina}

\author{
Mental health of medical students
}

$\mathrm{U}$ ma série de estudos apontam que a prevalência de transtornos ansiosos e depressivos na população de médicos e estudantes de medicina é maior em comparação à população geral. Devido a diversos fatores, o grupo dos profissionais da saúde figura dentro do grupo das profissões com maiores riscos de suicídio.

Uma revisão recente de artigos sobre estressores em estudantes de medicina mostrou que há fatores psicossociais, familiares, infraestruturais e relacionados à saúde. Dentre os mais relatados por estudantes estão a privação de sono, a solidão, a preocupação com o futuro e as altas expectativas dos pais.

Existem também evidências de que violência durante a vida universitária também são fatores relacionados à depressão, burnout e pior qualidade de vida dos estudantes. Em um estudo de corte-transversal realizado na Faculdade de Medicina da Universidade de São Paulo (FMUSP), exposição à violência física, psicológica ou sexual aumentou as chances de o estudante desenvolver depressão grave e burnout severo. Junto a isso, estudos internacionais descrevem uma alta prevalência de exposição à violência no curso médico. É importante notar que programas estratégicos podem reverter grande parte das fontes de estresse.

Visto isso, surge à necessidade de criação de programas de apoio ao estudante de medicina, para que se evite o desenvolvimento de transtornos psiquiátricos, assim como se identifique e acompanhe quem buscar auxílio. Tal necessidade está representada na iniciativa do GRAPAL (Grupo de Assistência Psicológica ao Aluno), criado em 1983 na FMUSP, com o objetivo de fornecer assistência psicológica a alunos e residentes da Faculdade.

Procurando entender os motivos pelos quais a saúde mental dos estudantes de medicina é prejudicada, mostramos nessa edição uma série de revisões e artigos originais sobre possíveis estressores presentes no curso médico e quais suas consequências no desenvolvimento emocional do estudante.

Desejamos a todos uma ótima leitura. 